\title{
Nudging Customers towards Healthier Choices: An Intervention in the University Canteen
}

\author{
Katarzyna Chapman (Corresponding author) \\ Department of Psychology, the College of Richard Collyer \\ Hurst Road, Horsham, West Sussex RH12 2EJ, UK \\ Tel: 44-137-284-4490Ｅ-mail: ktc@collyers.ac.uk \\ Jane Ogden \\ Department of Psychology, University of Surrey \\ Guildford, Surrey GU2 7XH, UK \\ Tel: 44-148-368-6929Ｅ-mail: J.Ogden@surrey.ac.uk
}

Received: January 16, 2012

Accepted: February 2, 2012 Published: May 1, 2012

doi:10.5539/jfr.v1n2p13

URL: http://dx.doi.org/10.5539/jfr.v1n2p13

The research was self-funded as part of doctoral degree undertaken at University of Surrey, UK

\begin{abstract}
The notion of nudge effects was investigated in two field experiments which focused on influencing customers' purchases by manipulating the location and availability of food in a University canteen setting. Study 1 manipulated the location of fruit and confectionary. Study 2 restricted the types of bread (i.e. brown only not white) that customers could choose for their sandwiches. The results of the Study1 showed that the fruit sales increased when positioned away from the checkouts. The majority of interviewed customers bought fruit intentionally but those who bought confectionary did it on impulse. In the Study 2, a restricted choice of baguettes did not reduce sales, with customers simply buying more brown baguettes. This increase did not persist after the intervention. Simple changes in the location and availability of food items can nudge the customers' purchases towards the choice of healthier options. There may be different processes that guide the purchase of fruit (intention/deliberation) and confectionary (impulse/reflex).
\end{abstract}

Keywords: Dietary intervention, Microenvironment, Impulse buying, Location, Availability, Nudge effects

\section{Introduction}

Research indicates that when individuals are not required to commit to dietary change, they seem unable to change what they eat in a sustained way (Kumanyika, Bowen, Rolls et al., 2000). Similarly, the rise in obesity and dietary related chronic conditions such as diabetes and coronary heart disease (WHO, 2003; NHES I; NHAHES IV: NHS, 2009) illustrates how unhealthy dietary habits can be resistant to manipulation. Yet, this is not the whole picture. A recent review of dietary change within randomised control trials (Chapman, 2010) supports the view that successful dietary change is possible, provided that individuals are highly motivated, are given a large amount of support during the intervention and actively strive to achieve their goals. Furthermore, studies of a diverse non-clinical sample (Chapman \& Ogden, 2009; Chapman \& Ogden, 2010) indicate that dietary changes are highly prevalent, sometimes unintentional and often experienced without an individuals' active involvement. For example, participants reported frequently making small changes to their diet such as a reduction in sugar or an increase in fruit and vegetables with minimal effort and planning. This type of change finds reflection in the nudge effects described by Thaler and Sunstein (2008) where individuals are nudged inconspicuously towards making choices that protect their health.

The research that precedes the nudge literature has aimed to investigate the effectiveness of interventions, which target populations, rather than the individual. These interventions have been conducted in microenvironments such as schools, workplaces, restaurants, grocery stores and in macroenvironments e.g. fortification of breads 
and grains with folic acid in the USA (Seymour, Yaroch, Serdula et al., 2004). A recent review of interventions in microenvironments (Stubenitsky, Aaron, Catt et al., 2002) categorized intervention strategies used in workplaces, universities, grocery stores and restaurants into information, incentives, availability and access. Information strategies included signs, posters, labels, shelf tags, menu symbols, flyers, booklets, TV, radio and newspaper advertisements. Incentive strategies included price reductions and promotions. Availability strategies included changing catering practices, recipes, and preparation methods, while access strategies included changing the location of items and bringing items to customers. The authors concluded that nutrition interventions had the greatest impact when they were conducted in 'limited access' sites, i.e. workplaces and universities, as opposed to grocery stores, as it was easier to maneuver customers towards making healthier choices. When perceived from the perspective of an individual, environmental interventions that focus on reduced availability and/or changed access to food items can be conceptualized as a result of nudging strategies developed purposefully by the local or a national authority.

One frequent focus of environmental interventions has been the promotion of fruit and vegetable consumption and reduction of confectionary intake (defined as food or drink that is calorie-dense and high in refined sugar) mainly through providing customers with nutrition information and offering them price reductions (e. g. Jeffery, French, Raether et al., 1994). However, there have also been interventions that used only availability and access to influence customers' choices (e. g. 13). In Hoerr and Louden's (1993) study, the latter strategies have been shown to be more effective than using information strategy. The authors tested the effect on sales in vending machines of the increased availability of high nutritional quality snacks in year 2 of the intervention versus providing additional nutrition information above each item in year 3. These interventions did not explore whether a strategy of changed location on it's own would influence customers' purchasing habits. For example, would changes in the location of fruit and confectionary make a difference in sales? The retail business has long been aware of the value of the space adjacent to checkouts as a place where the customer is 'forced' to look at the merchandise with the objective of tempting them to buy the offered items (Levy \& Weitz, 2004). The notion that customers are prone to impromptu purchases at the checkout had been supported in literature (e.g. Rook \& Fisher, 1995; Huddleston, Whipple \& VanAuken, 2004). A substantial body of research has been devoted to the phenomenon of impulse buying, defined as making unplanned and sudden purchases, which are initiated on the spot, and are accompanied by powerful urges and feelings of pleasure and excitement (Rook, 1997). Impulsive purchases are often triggered by the shopping environment (Beatty \& Farrell, 1998). The items sold at checkouts are positioned intentionally to trigger impulse buying. The items encountered most frequently at checkouts are magazines, chewing gum, confectionary, soft drinks and batteries (Front End Focus, 2008). These minor changes in the micro environment find reflection in the nudge theory and nudge strategies which usually consist of covert interventions that aim to change behaviour in subtle ways (Just \& Payne, 2009), To date, however, there are no published studies testing the effect of nudging changes in eating behavior by locating fruit at the checkouts and removing the confectionary from the checkout area. This could be due to commercial interests that dictate maximizing profit from sales regardless of the long term consequences for the health of the population.

In line with this emphasis on population-based intervention, the present paper reports the results from two experimental studies, which highlighted the impact of nudging in dietary behaviour with a focus on two aspects of the environment: the location of food (close to or away from the checkout) and the availability of food. In particular, the study aimed to assess whether manipulating these variables impacted upon the sales of fruit, confectionary and type of baguette (white vs brown) and also explored whether purchases of confectionary and fruit, following the intervention, were governed by impulse or whether they were made intentionally.

\section{Study 1. The Impact of Location on the Sales of Fruit and Confectionary}

\subsection{Method}

Ethical approval for both studies was obtained through the University Ethics Committee and the intervention took place in January - February 2009.

\subsubsection{Design}

An experimental ABA design - repeated measures - was used with the intervention lasting 3 weeks (A: Week $1 /$ B: Week 2 / A: Week 3). During this time the location of selected food items in the university canteen was manipulated in order to influence the consumers' purchases (near the checkout vs away from the checkout). A qualitative component was included in the study in the form of interviews conducted with 12 customers each day of the intervention to explore the reasons for their food purchases. 


\subsubsection{Procedure}

Week 1, Monday to Friday: Confectionary comprising of Kit Kats (chocolate biscuits) and assorted sweet biscuits were located by the checkouts; a basket with assorted fruit was located on a sideboard, away from the checkouts.

Week 2, Monday to Friday: Fruit basket was located by the checkouts; confectionary was located on the sideboard, away from the checkouts.

Week 3, Wednesday, Thursday, Friday, Monday and Tuesday (intervention was delayed due to university closure on Monday and Tuesday caused by heavy snow conditions): Confectionary were repositioned back by the checkouts and fruit was repositioned on the sideboard, away from the checkouts.

\subsection{Analysis}

Data was collected in the form of food items purchased on the basis of till data. The sales of fruit and confectionary were analysed using chi-square.

\subsubsection{Outcome variable}

Weekly sales of the targeted items: fruit and confectionary.

\subsection{Qualitative component}

\subsubsection{Participants}

For the qualitative component, 183 consumers in University canteen who bought Kit Kats, sweet biscuits, fruit or none of the above between 12 noon and $2 \mathrm{pm}$ of every day of the intervention were approached and asked to participate in the study. Three customers declined, 180 customers agreed to take part in the study $(98.4 \%)$. The researcher approached potential participants as they proceeded through checkout if they satisfied inclusion criteria. All students, visitors as well as academic, administrative and maintenance staff were included. The canteen employees were excluded. Customers who bought confectionary items or fruit as a snack rather than as a part of their lunch were not approached to give an interview, as their needs and intentions would have been different to the customers who bought fruit or confectionary in addition to another lunch item i.e. a sandwich or a hot meal option. The customers who bought both confectionary and fruit were not approached to give an interview either as they didn't have to make a choice between these two items.

\subsubsection{Interview schedule}

Twelve interviews were conducted on each day of the intervention during lunch time in one of the University of Surrey canteens, between 12 noon and $2 \mathrm{pm}$. Four consumers who bought confectionary, four customers who bought fruit and four customers who bought neither fruit or confectionary were asked to participate in the study. 120 participants were asked the following questions: 'Why did you buy Kit Kat/biscuits/fruit today?', 'Do you usually buy this item?' and 'What do you usually eat for lunch?' These questions were designed to establish whether the participants' purchase was made on impulse or intentionally. Participants were also asked whether they planned what they were going to eat for lunch: 'always', 'most of the time', 'sometimes', 'rarely' or 'never'. This question aimed to establish to what extend a participants' choice of lunch items was flexible. 60 participants who did not purchase fruit or confectionary item were asked whether they were tempted to buy any of these items.

\subsubsection{Analysis}

The interviews were analysed using content analysis. Participants' answers were coded and analysed using descriptive analysis, t-tests and one-way Anova. The differences in sales were analysed using Chi-square.

\subsection{Results}

In order to assess the impact of location of food on sales of food differences in sales of fruit vs confectionary according to location were assessed using chi square. The results are shown in Table 1.

\section{(Table 1)}

The weekly sales were compared: chi-sq $(2)=20.906, p=0.0001$. Post-hoc comparisons revealed statistically significant difference in sales between Week 1 and 2 (chi-sq $(1)=11.997, \mathrm{p}=.0005)$ and week 2 and 3 (chi-sq $(1)=18.535, p=.0001)$. There was no statistically significant differences between Week 1 and 3 (chi-sq $(1)=$ $0.883, \mathrm{p}=.347)$. These results showed a significant effect of the intervention as the sales of fruit and confectionary changed in the second week. These changes however, were not in the predicted direction. The sales of both fruit and confectionary were lower when these items were positioned by the checkouts. The sales of 
both fruit and confectionary increased when they were positioned on the sideboard, away from the checkouts. When the fruits were positioned by the checkouts in the second week, the sales decreased from 372 items to 275 items, which constitutes a difference of $26.1 \%$. When the confectionary was moved away from the checkouts, sales in the second week increased from 197 items to 225 items, which constitutes the difference of $14.2 \%$. Thus the observed effect was larger for fruit sales.

\subsubsection{Qualitative data including content analysis of the interviews with the participating customers}

96 female and 84 male customers were interviewed during the intervention. Most of them were students (62.2\%) but members of staff were also well represented (34.4\%). The large majority of participants were of white ethnic origin (73.3\%) and a large minority was of Asian ethnic origin (16.1\%). Most of participants declared their income per year as lower than $£ 10000$ but $36.1 \%$ of participants declared their income as above $£ 20000$. A large majority (64.4\%) said that they were eating at the canteen several times a week. Full details are shown in Table 2 .

\section{(Table 2)}

The results obtained from 120 participants who bought either a confectionary item or fruit showed that the majority of them when purchasing a confectionary item did it on impulse $[N=36(30 \%)]$ while the participants who purchased fruit, tended to do intentionally [ $\mathrm{N}=41(43.2 \%)]$. The differences were statistically significant (chi-sq $(1)=9.701, \mathrm{p}=.001)$. The results are shown in Figure 1.

(Figure 1)

Within the group of participants who did not purchase either a confectionary item or fruit with their lunch $(N=$ 60). A large majority said that they were not tempted to buy a confectionary item or fruit. There were more participants who said they were tempted to buy a confectionary item $(11.7 \%)$ that the participants who were tempted to buy fruit $(6.7 \%)$ but the difference was not statistically significant. Full results are shown in Table 3 .

(Table 3)

\subsection{Discussion}

The results of Study 1 confirmed the prediction that there will be a difference in sales figures of fruit and confectionary depending on their location. However, these results did not confirm a second prediction that the sales figures will rise when items are positioned close to the checkouts. The latter was particularly salient with the sales of fruit, which fell significantly when displayed by the checkouts and rose when displayed on the sideboard. This pattern was also evident but to a lesser extent in the sales of confectionary.

Retailers are aware of the value of checkout space and are keen to maximize their profits by reserving it for products that are known to elicit impulse buying. Confectionary and magazines, according to Front End Focus study (2008) based on sales data from 565 US leading retailers, are bought most frequently and are classed as 'high impulse' purchase by the industry. The study compared the sales of 18 categories of products sold at checkouts e.g. candy, mints, books, batteries, phone cards, cosmetics, etc. and listed 45 more unusual categories of items that had appeared by checkout stands, such as children's' toys, air fresheners, pizza cutters, windshield solvents, etc. Fruit did not feature among any of these categories and perhaps that is why there had been no studies conducted on the effect on sales of locating fruit in the checkout area.

A possible reason why fruit and confectionary sales declined when either of these items was located by the checkouts may have been due to the efficient cashier service in the university canteen. It meant that customers were not subjected to a long waiting time; therefore the possibility of indulging in an impulse buy was reduced. The time spent queuing at the checkout is an important variable in impulse buying: 5-7 minutes is an average not too long to upset the customers but long enough to tempt them to purchase additional items found at the checkout (Front End Focus, 2008).

The results, showing that participants tended to buy confectionary items on impulse and to purchase fruit intentionally, supported data on impulse buying of confectionary at checkouts. A more surprising result was that the sales of fruit rose when it was positioned on the sideboard. One of the reasons could have been that the fruit was placed in an aesthetically appealing basket rather than split into separate boxes containing bananas, oranges or apples. This arrangement gave an impression of a home fruit bowl rather than the fruit display in a supermarket. Having all fruit in one basket was appealing but it also meant that the process of choosing a particular fruit needed additional time - a preferred fruit might have been underneath other fruit, the fruit quality had to be evaluated, a banana (most popular choice of fruit) had to be detached from a bunch, etc. These actions are relatively time consuming and cannot be performed if there is a pressure to proceed quickly in a queue. 
These actions also require a degree of deliberation and by definition are at the other end of the spectrum to impulsive behaviour.

\section{Study 2. The Impact of Availability on Sales of Baguettes}

\subsection{Design and procedure}

An experimental, before and after design with repeated measures was used. The canteen removed for one day the choice of white baguettes from their sandwich bar. Instead, the customers were offered brown baguettes only. The sales of brown baguettes were recorded. There were no interviews conducted on the day when the brown baguettes were sold as the researcher did not want to influence the future choices that the customers might make relating to the kind of baguette they choose for their lunch.

\subsection{Outcome variable}

Sales of white and brown baguettes.

\subsection{Analysis}

Data was collected in the form of food items purchased on the basis of till data. The sales of white and brown baguettes were analysed using chi-square.

\subsection{Results}

The number of sales of both white and brown baguettes on different days is shown in the Table 4 .

(Table 4)

These results showed that the sales of brown baguettes on the day of the intervention were almost as high as the number of total sales of white and brown baguettes on any other day indicating that restricting the availability of white baguettes resulted in a shift in purchases towards the healthier option. However, the intervention did not seem to change customers' preferences as this increase in the sales of brown baguettes did not persist after the intervention.

\subsection{Discussion}

This intervention aimed to test the possibility of nudging strategy on customers' dietary choices in the short term (on the day of the intervention) and in the long term (post intervention). The intervention showed that it was possible to guide customers towards making healthier choice when other options were not available. The customers, no doubt, were aware of this situation but they did not resist it. The sales of brown baguettes on the day of the intervention were almost as high as the combined sales of white and brown baguettes on other days. The customers did have other choices as the sandwich bar also offered ciabattas, focaccias and crusty rolls, so if they did not like brown baguettes they could ask to have their sandwich made in a different type of bread. And yet they didn't, which suggests that habits can be easily disrupted. The one day intervention was not enough; however, to change customers preferences in the long term as the sales of brown baguettes did not increase in the days following the intervention. Despite the fact that the canteen offered in their sandwich bar the choice of other breads in addition to baguettes and by implication the customers choices were not reduced radically, when the length of the intervention was being negotiated, the catering manager agreed to just one day of removing white baguettes from the menu as not to disrupt normal service for too long and not to risk the loss of revenue. However, irrespective of these restrictions the results demonstrated that nudging the customers towards healthier choices is a promising strategy in guiding customers' dietary behaviour. This conclusion supports findings of interventions in microenvironments that demonstrated availability and location to be effective strategies in influencing customers' purchases (e.g. Hoerr \& Louden, 1993).

\section{General Discussion}

Study 1 and 2 aimed to influence consumers' purchases at the university canteen by manipulating the location of fruit and confectionary and by nudging the customers towards a healthier dietary choice (brown baguettes) during lunchtime. The results confirmed the predictions that there would be a difference in sales of fruit and confectionary depending on their location, and that the customers would purchase more brown baguettes if white baguettes are not available. However, contrary to predictions, there was a decrease in sales of items that were positioned by the checkouts and there was not an increase in sales of brown baguettes after the intervention.

The fact that the sales of fruit rose in the weeks when it was located away from the checkouts indicates that there may be different processes that guide the purchase of fruit and confectionary. Fruit belongs to a shopping category that requires greater 'elaboration' in decision making and by implication does not lend itself for purchasing at the checkout (Miranda, 2008). Confectionary, on the other hand belongs to a shopping category 
that is characterized by 'impulse buying'. 'Impulse buying' has been studied extensively within marketing and psychology. Marketing has relied on impulse buying for the profit margins. Some US statistics claim that $62 \%$ of sales in supermarkets are a result of impulsive buying (Abrahams, 1997). Psychology has contributed to the understanding of this phenomenon by developing reflective-impulsive model (RIM), (Strack \& Deutsch, 2002) which sees the behaviour as a joint outcome of two systems. The impulsive system guides quick and spontaneous behaviour while the reflective system guides intentional and deliberate actions. The ratio of impulsive to reflective component in behaviour depends on the regulatory strength of the reflective system. Reflective system has limited capacity and when it gets depleted through i.e. having to resist temptation, its regulatory power diminishes (Baumeister, 2002). The RIM has proved particularly useful in the study of consumer behaviour and there is now convincing evidence that having to make choice depletes the self-regulatory resource, especially when there are more than two options to choose from (Moller, Deci \& Ryan, 2006; Vohn, Baumeister, Twenge et al., Unpublished manuscript). This suggests that customers would not necessarily feel better served when faced with multiple choices and that it would be easier for them to self-regulate if they had to chose from not more than a couple of options.

Study 2 also showed that a simple intervention can change dietary choices but indicated that although single event may disrupt habitual behaviour, it may not change it in the long term. In a recent study, Lally and colleagues (2008) endeavored to model the habit formation process by asking participants to repeat a novel behaviour (either eating or exercise) every day in the same context for 12 weeks. They found that it took on average 70 days to develop a habit and that a single failure to perform the behaviour had very little impact on the development of the habit. This evidence may explain why buying a brown baguette on a single occasion would not change a long ingrained habit. The fact that a single disruption is unlikely to produce sustained behaviour change should not be taken with resignation but it should be perceived as a prospective trigger which, if followed by continued changes in the environment, has a potential for long term dietary behaviour change.

The notion of nudging strategies as a viable way of health interventions may seem aversive in the light of widely held views that individuals should be free from the patronizing influence of the state. Yet the same individuals view the provision of state-provided health care (in the UK) for granted. In order to reconcile these two divergent expectations, Thaler and Sunstein (2008) propose 'libertarian paternalism' as an ideal that can be justified and viable for both the state and the individual. In their view, the individual can be guided to make choices that have been judged by society as beneficial to long term health. This is the task for 'choice architects'. Their role is to design an environment in which an individual is nudged to make choices that promote health and well being. Thaler and Sunstein (2008) argue that nudging people preserves the ethos of free will and freedom of choice, whilst gently steering them onto a path that benefits the individual's health.

A number of field studies reviewed by Just and Payne (2009), suggest a variety of nudge strategies that may be effective and acceptable to the consumer. These include the provision of small plates and utensils in 'all you can eat' restaurants, and positioning buffet food further away from the customers. Another idea is offering customers who purchase their food in school or work cafeterias the option of 'restricted debit cards'. The restriction refers to the limited budget available to spend on food and beverages deemed as unhealthy. This way, all customers can retain freedom of choice, while some customers will take up the restricted debit card option as a way of self-regulating.

\section{Conclusion}

Although literature indicates that dietary habits may be difficult to change, a recent study suggests that many changes occur across the life span and that some of these occur without effort or intentionality The present study aimed to explore the impact of two simple changes in the environment and show that manipulation of both the location and availability of food can influence customers' purchases towards the choice of healthier options. These findings contribute evidence to the growing momentum in embracing a new development of creating environments that 'nudge' customers into making beneficial choices for their long term health prospects.

\section{References}

Abrahams, B. (1997). It's all in the mind. Marketing, 27, 31-33.

Baumeister, R. (2002). Ego-depletion and self-control failure: An energy model of the self's executive function. Self and Identity, 1, 129-36. http://dx.doi.org/10.1080/152988602317319302

Beatty, S. E., \& Ferrell, M. E. (1998). Impulse buying: Modelling its precursors. Journal of Retailing, 74, 169-91. http://dx.doi.org/10.1016/S0022-4359(99)80092-X 
Chapman, K., \& Ogden, J. (2009). How do people change their diet? An exploration into mechanisms of dietary change. Journal of Health Psychology, 14(8), 1229-42. http://dx.doi.org/10.1177/1359105309342289

Chapman, K., \& Ogden, J. (2010). The prevalence of mechanisms of dietary change in a community sample. Appetite, 55, 447-53. http://dx.doi.org/10.1016/j.appet.2010.08.006

Chapman. K. (2010). Can people make healthy changes to their diet and maintain them in the long term? A review of the evidence. Appetite, 54, 433-41. http://dx.doi.org/10.1016/j.appet.2010.01.017

Choumenkovitch, S. F., Selhub, J., Wilson, P. W. F., Rader, J. I., Rosenberg, I. H., \& Jacques, P. F., (2002). Folic acid intake from fortification in the United States exceeds predictions. Journal of Nutrition, 132, 2792-8.

Front End Focus. (2008). Best Practices for Superior Checkout Merchandising. https://www.frontendfocus.com/documents/publications/Front-End\%20Focus\%20Overall\%20Study.pdf.

Hoerr, S. M., \& Louden, V. A. (1993). Can nutrition information increase sales of healthful vended snacks? Journal of School Health, 63, 386-90. http://dx.doi.org/10.1111/j.1746-1561.1993.tb06167.x

Huddleston, P., Whipple, J., \& VanAuken, A. (2004). Food store loyalty: Application of consumer loyalty framework. Journal of Targeting, Measurements and Analysis for Marketing. 12, 213-30. http://dx.doi.org/10.1057/palgrave.jt.5740110

Jeffery, R. W., French, S. A., Raether, C. \& Baxter, J. E. (1994). An environmental intervention to increase fruit and salad purchases in cafeteria. Preventive Medicine, 23, 788-92. http://dx.doi.org/10.1006/pmed.1994.1135

Just, D. R., \& Payne, C. P. (2009). Obesity: Can Behavioral Economics Help? Annals of Behavioral Medicine, 38, Suppl(1), S47-S55.

Kumanyika, S. K., Bowen, D., Rolls, B. J., Van Horn, L., Perri, M. G., Czajkowski, S. M., \& Schron, E. (2000). Maintenance of dietary behaviour change. Health Psychology, 19(Suppl.), 42-56. http://dx.doi.org/10.1037/0278-6133.19.Supp11.42

Lally, P., van Jaarsveld, C., Potts, H., \& Wardle, J. (2008). Can we model the habit formation process? Annals of Behavioral Medicine, Suppl (1), S212.

Levy, M., \& Weitz, B. A. (2004). Retailing Management. McGraw-Hill, New York.

Miranda, M. (2008). Determinants of shoppers' checkout behaviour at supermarkets. Journal of Targeting, Measurement and Analysis for Marketing, 16,312-21. http://dx.doi.org/10.1057/jt.2008.23

Moller, A. C., Deci, E. L., \& Ryan, R. M. (2006). Choice and ego-depletion: The moderating role of autonomy. Personality and Social Psychology Bulletin, 32, 1024-36. http://dx.doi.org/10.1177/0146167206288008

NHANES IV. (1999-2000). Fourth National Health and Nutrition Examination Survey. U.S. Department of Health and Human Services, Centres for Disease Control and Prevention, National Centre for Health Statistics.

NHES I. (1959). First Health Examination Survey. U.S. Department of Health and Human Services. National Center for Health Statistics. Centers for Disease Control and Prevention.

NHS Information Centre, Lifestyle Statistics. (2009). Statistics on obesity, physical activity and diet: England, February 2009.

Rook, D. W. (1987). The buying impulse. Journal of Consumer Research, 14, 189-99. http://dx.doi.org/10.1086/209105

Rook, D. W., \& Fisher, R. (1995). Normative influences on impulsive buying behaviour. Journal of Consumer Research, 22, 305-13. http://dx.doi.org/10.1086/209452

Seymour, J. D., Yaroch, A. L., Serdula, M. D., Blanck, H. M., \& Khan, L. K.(2004). Impact of nutrition environmental interventions on point-of-purchase behaviour in adults: a review. Preventative Medicine, 39, S108-S136. http://dx.doi.org/10.1016/j.ypmed.2004.04.002

Strack, F., \& Deutsch, R. (2004). Reflective and impulsive determinants of social behavior. Personality and Social Psychology Review, 8, 220-47. http://dx.doi.org/10.1207/s15327957pspr0803_1

Stubenitsky, K., Aaron, J. L., Catt, S. L., \& Mela, D. J. (2000). The influence of recipe modification and nutritional information on restaurant food acceptance and macronutrient intakes. Public Health Nutrition, 3, 2001-9. http://dx.doi.org/10.1017/S1368980000000239

Thaler, R. H., \& Sunstein, C. A. (2008) Nudge: improving decisions about health, wealth, and happiness. New Haven: Yale University Press. 
Vohs, K. D., Baumeister, R. F., Twenge, J. M., Nelson, N. M., Rawn, C. D., Schmeichel, B. J., \& Tice, D. M. (2007). Making choices impairs subsequent self-control: A limited resource account of decision-making, self-regulation, and active initiative. Manuscript submitted for publication.

WHO (2003). World Health Organization. Obesity and Overweight. Geneva.

Table 1. Number of sales of fruit and confectionary at the university canteen during the three weeks of intervention

\begin{tabular}{llll}
\hline & Week 1 & Week 2 & Week 3 \\
\hline Fruit & $372(\mathrm{~S})$ & $275(\mathrm{C})$ & $360(\mathrm{~S})$ \\
\hline Confectionary & $197(\mathrm{C})$ & $225(\mathrm{~S})$ & $169(\mathrm{C})$ \\
\hline
\end{tabular}

(S) - location of food item on the sideboard

(C) - location of the food item by the checkouts

Table 2. Participants' demographic characteristics

\begin{tabular}{|c|c|c|c|}
\hline Variable & & $\mathbf{N}$ & $(\%)$ \\
\hline \multirow[t]{2}{*}{ Sex } & Female & 96 & 53.3 \\
\hline & Male & 84 & 46.7 \\
\hline \multirow[t]{5}{*}{ Age } & $\leq 23$ & 66 & 36.7 \\
\hline & $24-32$ & 56 & 1.1 \\
\hline & $33+$ & 58 & 32.2 \\
\hline & Mean (standard deviation) & 31.2 & 12.4 \\
\hline & Range & $18-71$ & \\
\hline \multirow[t]{4}{*}{ Ethnic origin } & White & 132 & 73.3 \\
\hline & Asian & 29 & 16.1 \\
\hline & Black & 7 & 3.9 \\
\hline & Other & 12 & 6.7 \\
\hline \multirow[t]{3}{*}{ Affiliation } & Student & 112 & 62.2 \\
\hline & Staff & 62 & 34.4 \\
\hline & Visitor & 6 & 3.3 \\
\hline \multirow[t]{3}{*}{ Income per year } & Below $£ 10000$ & 92 & 51.1 \\
\hline & $£ 10000-£ 20000$ & 23 & 12.8 \\
\hline & Over $£ 20000$ & 65 & 36.1 \\
\hline \multicolumn{4}{|c|}{ Frequency of eating at the canteen } \\
\hline & Less than $1 \mathrm{x}$ month & 19 & 10.6 \\
\hline & Less than $1 \mathrm{x}$ week & 28 & 15.6 \\
\hline & Several times per week & 116 & 64.4 \\
\hline & Nearly every day & 17 & 9.4 \\
\hline
\end{tabular}

Table 3. The group of participants who did not buy a confectionary item or fruit and who declared either feeling tempted or not tempted to buy either of these items

\begin{tabular}{rrrrrrr}
\hline & \multicolumn{2}{c}{ Confectionary } & \multicolumn{2}{c}{ Fruit } & Total \\
\cline { 2 - 6 } & Tempted & Not tempted & Tempted & Not tempted & \\
& $\mathbf{N}^{\mathbf{0}}(\%)$ & $\mathbf{N}^{\mathbf{0}}(\%)$ & $\mathbf{N}^{\mathbf{0}}(\%)$ & $\mathbf{N}^{\mathbf{0}}(\%)$ & $\mathbf{N}^{\mathbf{0}}(\mathbf{\%})$ \\
\hline Participants & $7(11.7)$ & $53(88.3)$ & $4(6.7)$ & 56 & $(93.3)$ & $60(100)$ \\
\hline
\end{tabular}


Table 4. A number of sales of white and brown baguettes on the day of the intervention, pre-intervention and post-intervention

\begin{tabular}{|c|c|c|c|c|c|}
\hline & $\begin{array}{r}\text { Thursday } \\
\text { one week } \\
\text { before the } \\
\text { intervention day }\end{array}$ & $\begin{array}{r}\text { Wednesday } \\
\text { one day } \\
\text { before the } \\
\text { intervention day }\end{array}$ & $\begin{array}{r}\text { Thursday } \\
\text { Intervention } \\
\text { day }\end{array}$ & $\begin{array}{r}\text { Friday } \\
\text { one day } \\
\text { after the } \\
\text { intervention day }\end{array}$ & $\begin{array}{r}\text { Thursday } \\
\text { one week } \\
\text { after the } \\
\text { intervention day }\end{array}$ \\
\hline $\begin{array}{l}\text { Brown } \\
\text { baguettes }\end{array}$ & 73 & 63 & 135 & 71 & 72 \\
\hline $\begin{array}{l}\text { White } \\
\text { baguettes }\end{array}$ & 70 & 58 & 0 & 75 & 80 \\
\hline Total & 143 & 121 & 135 & 146 & 152 \\
\hline
\end{tabular}

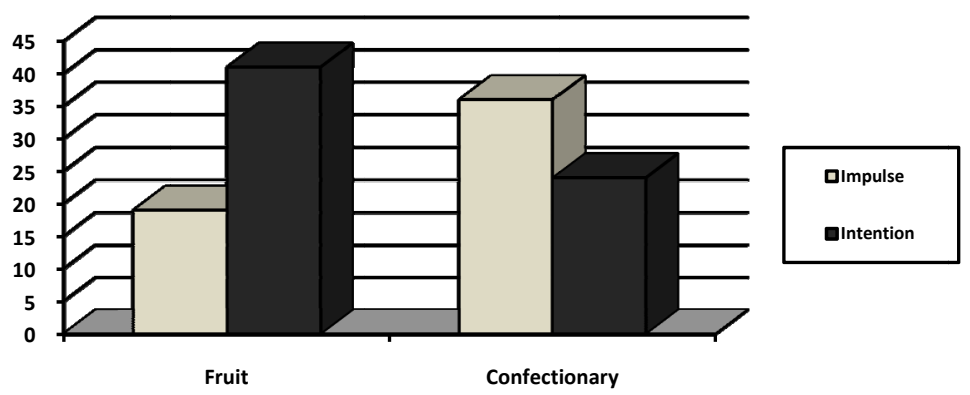

Figure 1. The number of sales of fruit and confectionary lead by impulse or intention during the studied 3-week period 